\title{
PINGENTE RELICÁRIO
}

Natascha Scagliusi

Pontifícia Universidade Católica do Rio de Janeiro

Núcleo de Experimentação Tridimensional

natascha.scagliusi@gmail.com

Resumo: O Pingente Relicário é resultado de uma pesquisa experimental com o objetivo de explorar características da Microtomografia Computadorizada, do Processamento Digital de Imagens e da Impressão 3D que, ao trabalharem em integração, extrapolam aspectos da fabricação convencional de joias. Estas distinções podem ser descritas como a viabilidade de fabricação de geometrias altamente intrincadas e o desenho a partir de complexas estéticas oriundas da natureza. $O$ experimento desenvolveu-se em busca da máxima exploração do potencial técnico das tecnologias de digitalização e materialização, culminando em uma solução estética diferenciada. O produto resultante é uma joia viável de ser pensada e produzida somente a partir da associação destas tecnologias.

Palavras-chave: Design de Joias; Escaneamento 3D; Microtomografia Computadorizada; Impressão 3D.

\begin{abstract}
The Reliquary Pendant is the result of experimental research that focused on exploring characteristics of computed microtomography, digital image processing, and $3 D$ printing that together exceed conventional jewelry fabrication techniques. These distinctions involve highly intricate geometries and design from forms with particular nature aesthetics. The experiment was developed in pursuit of the maximum exploitation of both scanning and materialization technologies' technical potential and culminated in a distinct aesthetic solution. The resulting product is a jewel that only the combination of these technologies can design and produce.
\end{abstract}

Keywords: Jewelry Design; 3D Scanning; Computed Microtomography; 3D printing. 


\section{INTRODUÇÃO}

A Microtomografia Computadorizada vem sendo largamente apropriada por diversas áreas das ciências biológicas e de materiais para o estudo de microestruturas. Sua aplicação vem gradualmente expandindo-se a outras áreas à medida que o equipamento se populariza. Ao beneficiar-se das propriedades de interação dos Raio-x com a matéria, a técnica é muito eficaz para a digitalização não-invasiva e nãodestrutiva de amostras que contenham detalhes internos não-aparentes, espessuras ou até mesmo geometrias intrincadas (STOCK, 2009). Assim como a tomografia médica, os resultados desta observação são imagens bidimensionais; as camadas que integralizam o objeto estudado e que, aliadas ao Processamento Digital de Imagens, permitem a reconstrução tridimensional virtual do volume da amostra.

As geometrias adquiridas pela integração da Microtomografia Computadorizada ao Processamento Digital de Imagens podem ser apoderadas pelo design de joias, demonstrando que uma forma natural de estrutura complexa de difícil obtenção a partir de modelagem CAD ou escaneamento por luz ou infravermelho, poderá agora ter sua estética apropriada pelo designer em suas criações.

Como tanto a Microtomografia Computadorizada quanto a impressão 3D são processos complexos que lidam no mesmo nível de eficiência com geometrias intrincadas e construção de imagens e modelos por camadas, é possível extrapolar o máximo de aproveitamento do seu intercâmbio, tanto no reconhecimento quanto na construção de formas.

Vale ressaltar que a impressão 3D é uma tecnologia de manufatura aditiva que liberta o processo do design de antigas restrições e permite a construção de formas que, anteriormente, seriam impraticáveis de se fabricar (HOPKINSON, HAGUE e DICKENS, 2006).

\section{DESENVOLVIMENTO}

As formas naturais historicamente fazem parte do repertório de inspirações da joalheria. Desde o surgimento das técnicas manuais de fabricação, passando pelo advento do Desenho Assistido por Computador, até o momento atual em que equipamentos de escaneamento tridimensionais iniciam o seu processo de popularização, os motivos naturais são temas recorrentes no design de joias. Os escâneres 3D, que são tecnologias de captura de superfície, tornaram possível a digitalização de objetos naturais. Contudo, a captura de formas de geometria muito intrincadas é inviável para estes escâneres. Da mesma forma, é um desafio modelar digitalmente ou manualmente em cera formas orgânicas compostas por estruturas labirínticas e de espessura variante. Os recursos da Microtomografia Computadorizada aliados ao Processamento Digital de Imagens integram uma técnica de digitalização tridimensional, que viria a contribuir para expansão das possibilidades de trabalho de joalheria com formas naturais.

A metodologia utilizada na transposição do real para o virtual segue a proposta pelos estudos de Processamento Digital de Imagens de Paciornik e Maurício (2004), complementada pela fase de design do experimento, sugerida por Stock (2009). Na Figura 1 tem-se um fluxograma que ilustra as fases do processo. 


\begin{tabular}{|l|}
\hline Legenda: \\
fases do experimento \\
Planejamento \\
do experimento \\
Formação \\
da imagem \\
Digitalização \\
da imagem \\
Processamento \\
da imagem \\
Análise \\
da imagem
\end{tabular}

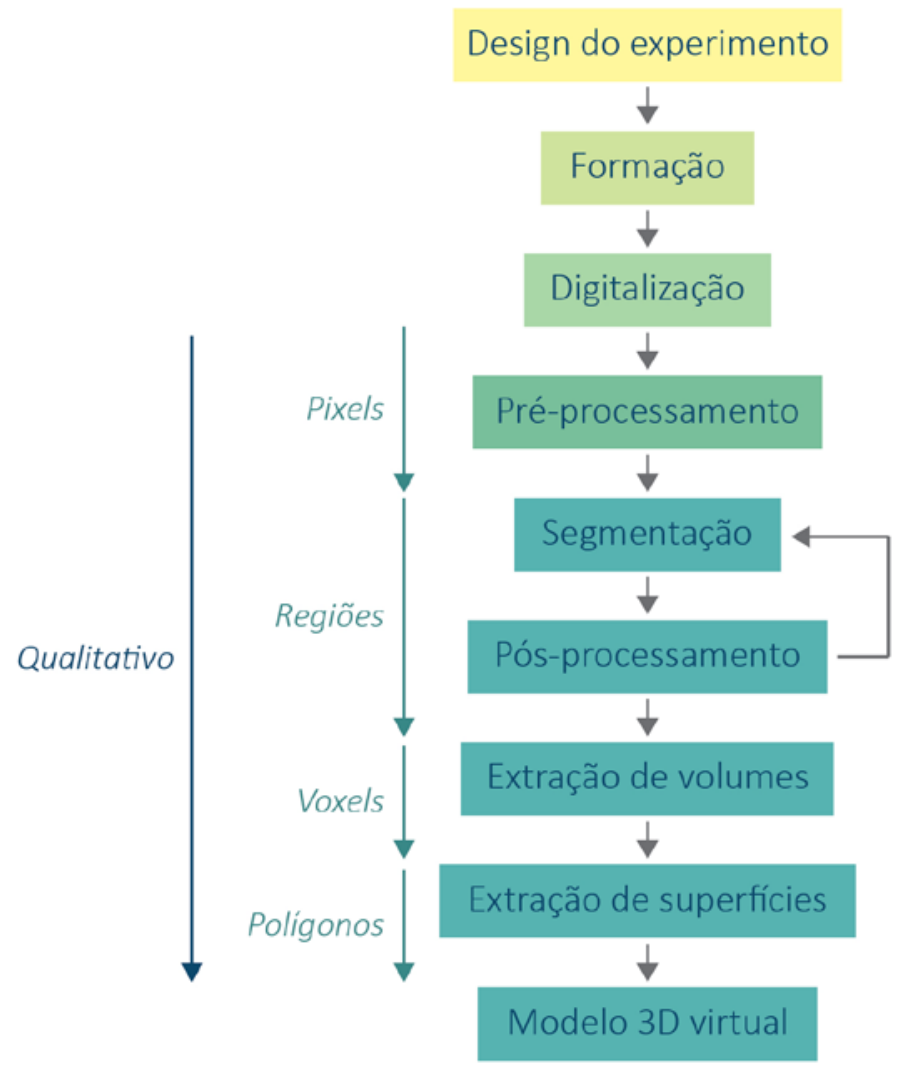

Figura 1 - Metodologia proposta para a digitalização de amostras.

Fonte: Elaborado pelos autores, com base nos estudos de Paciornik e Maurício e Stock.

Como se pode verificar na Figura 2, uma amostra vegetal com características bastante desafiadoras foi escolhida para o experimento. Os arquivos resultantes da digitalização são ilustrados na Figura 3, e permitem a intervenção em seu design pelo auxílio de programas de desenho assistido por computador e escultura digital.
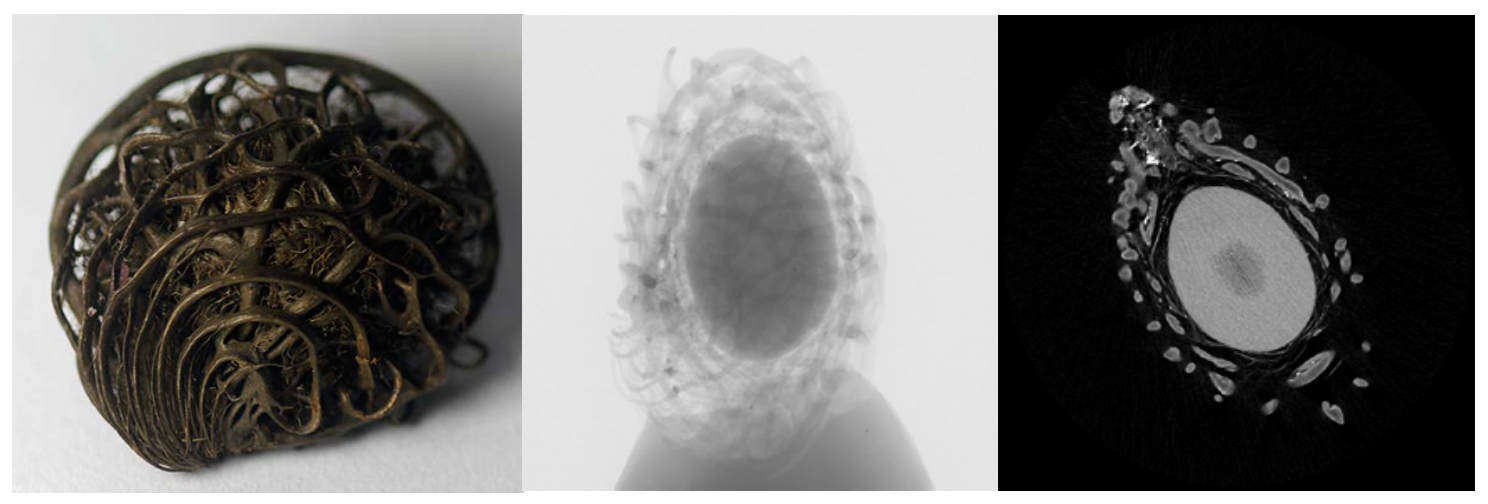

Figura 2 - Semente do gênero Spondia, projeção e camada adquiridas por Microtomografia Computadorizada.

Fonte: Elaborado pelos autores, com base na pesquisa realizada. 


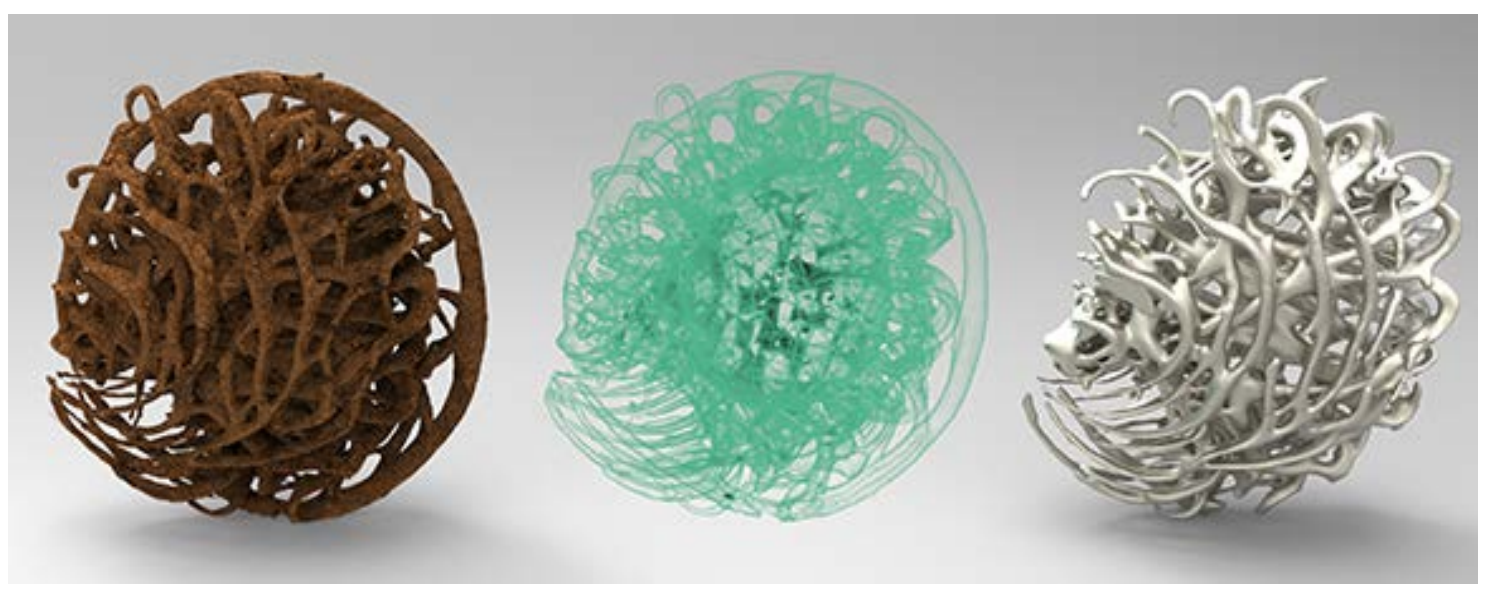

Figura 3 - Render de modelos tridimensionais virtuais da semente, ilustrando a possibilidade de digitalizar o seu interior e aplicar modificações ao modelo original.

Fonte: Elaborado pelos autores, com base na pesquisa realizada.

Além de ampliar a diversidade e a complexidade das formas alcançáveis no design de joias, esta tecnologia torna possível também explorar as vantagens da padronização e fabricação em série das tecnologias digitais. Seguiu-se, então, à opção de retirar e acrescentar elementos do modelo digitalizado, a modificação de formas e alteração de sua escala, manipulando, acrescentando e aperfeiçoando aspectos como diminutos detalhes e texturas. A Figura 4 ilustra uma sequência de intervenções no modelo digital original para o design da joia, assim como o planejamento para a montagem das metades através de encaixe e solda.

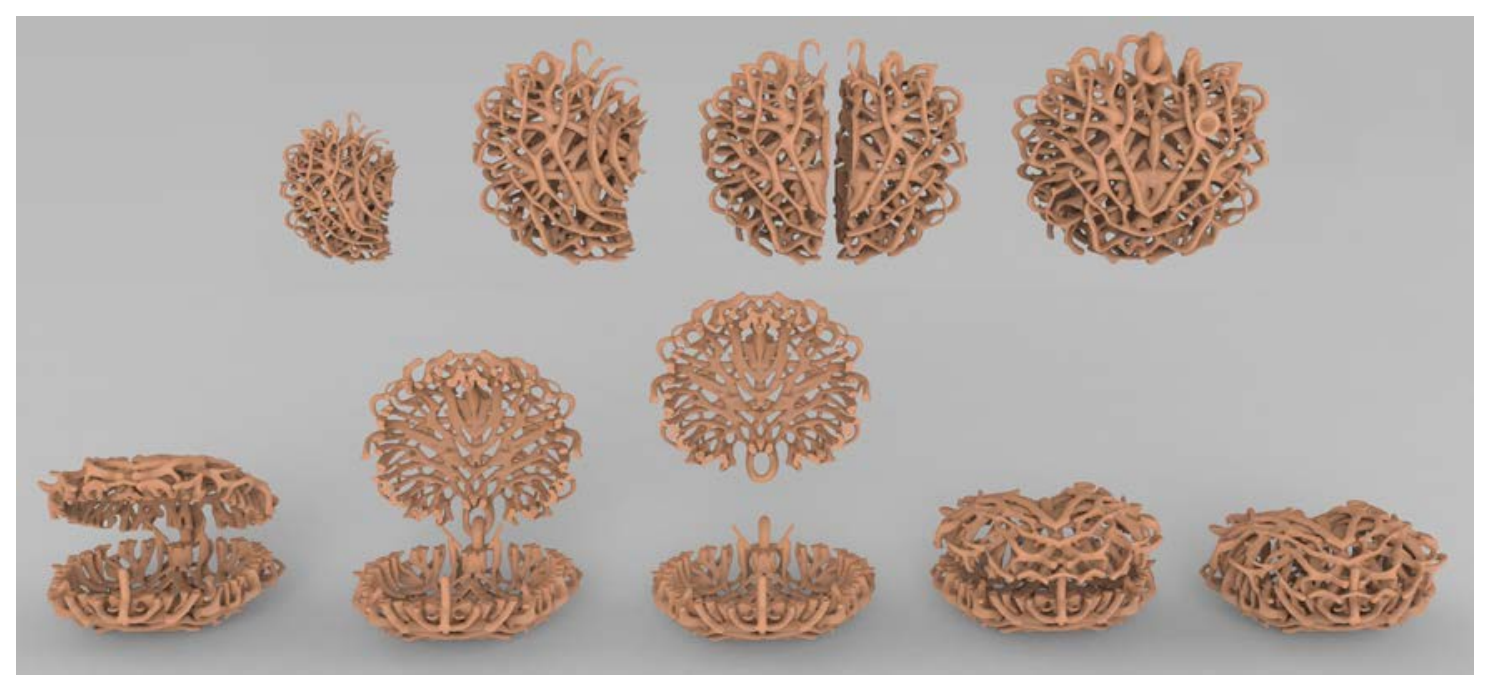

Figura 4 - Render de sequência de intervenções no modelo digital da semente e planejamento de montagem de partes.

Fonte: Elaborado pelos autores, com base na pesquisa realizada.

Para a fabricação do modelo tridimensional do Pingente Relicário, foi escolhida a tecnologia de impressão 3D Digital Light Processing. Este tipo de impressão permite a produção de joias pelos processos de fundição convencionais, quer seja na confeç̧ão de modelos tridimensionais positivos para a obtenção dos negativos em silicone - 
adotados para a replicação de modelos em cera - ou, tal como no caso do pingente em questão, na fabricação de modelos que podem ser impressos em uma resina que viabiliza a sua fundição direta. O modelo impresso, o resultado de sua fundição e montagem, assim como o produto da finalização da peça com cravações, polimentos e banhos podem ser aferidos, respectivamente, nas Figura 5, 6 e 7. As dimensões da peça final são ilustradas pela Figura 9.

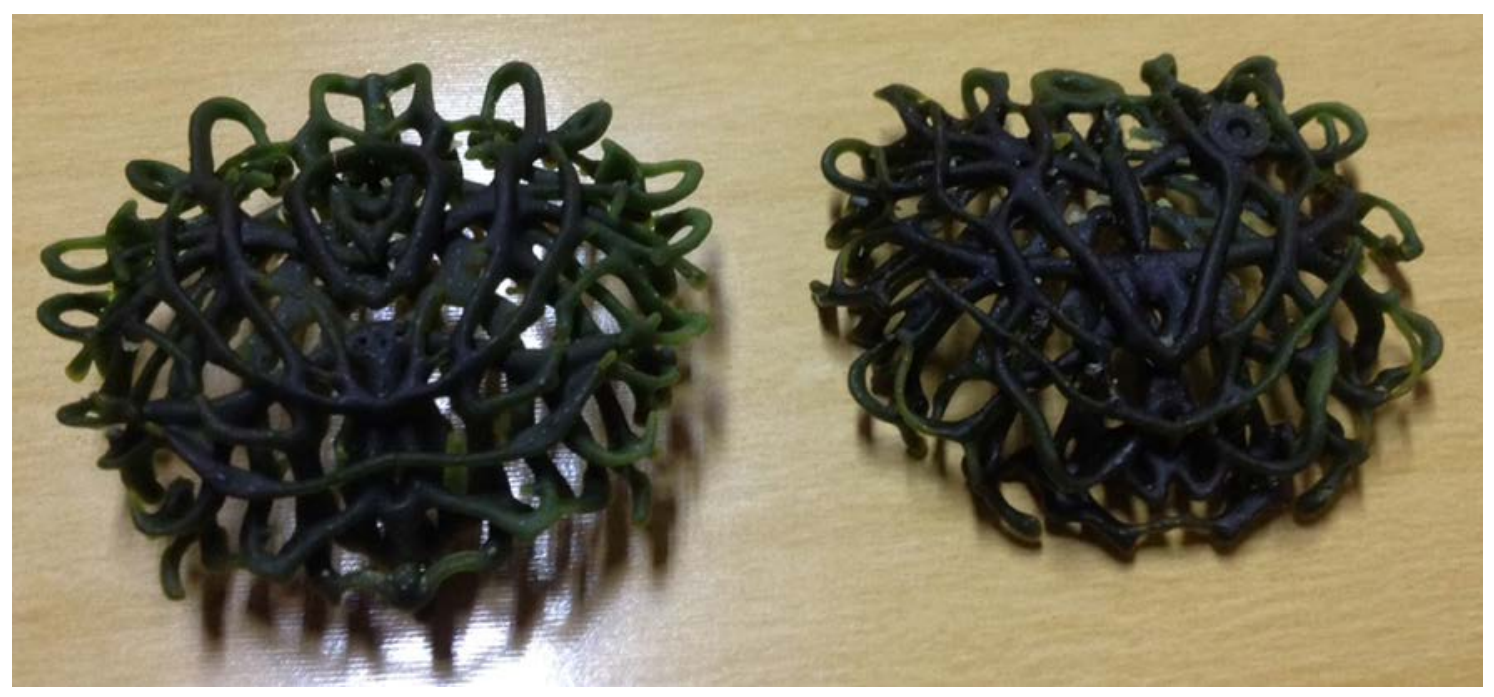

Figura 5 - Impressão 3D por das metades que integram a joia.

Fonte: Elaborado pelos autores, com base na pesquisa realizada.

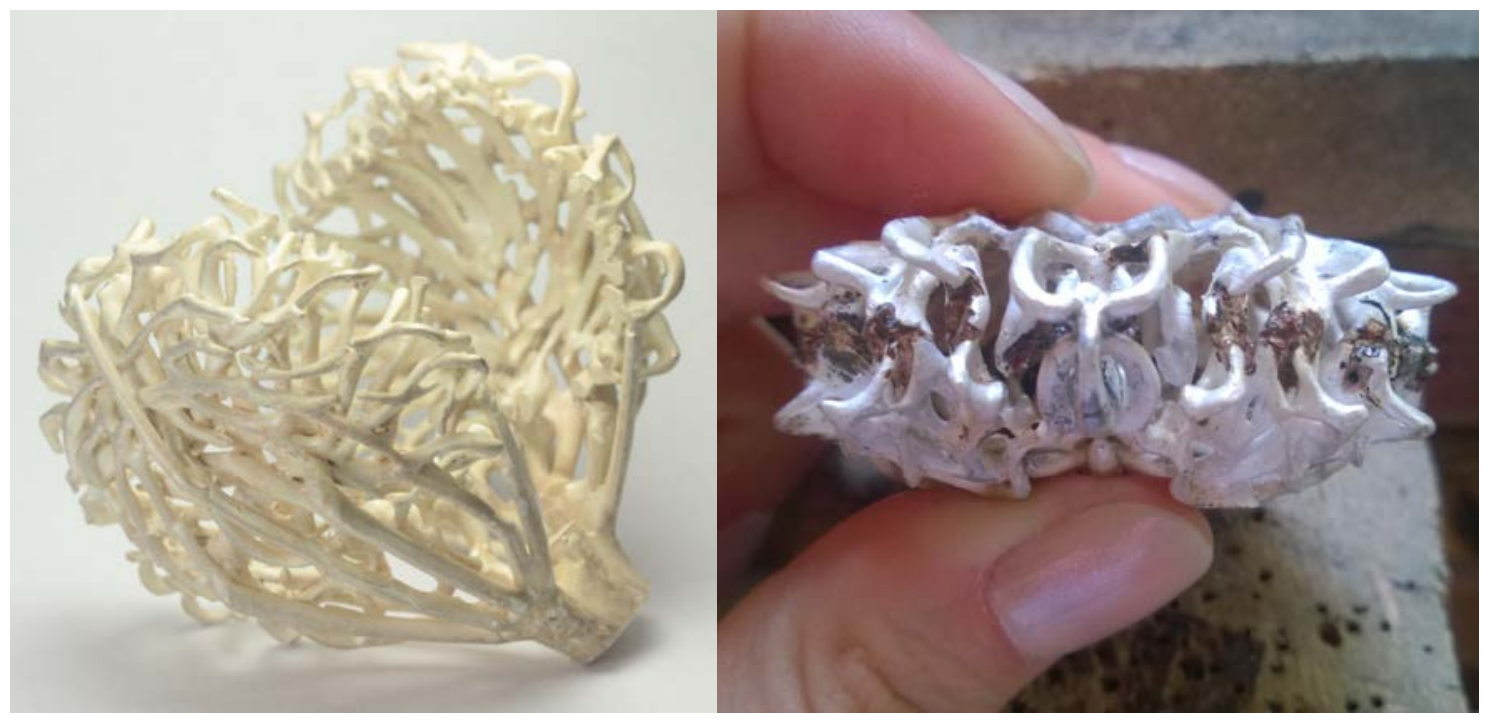

Figura 6 - Fundição e soldagem das partes que compõem a peça.

Fonte: Elaborado pelos autores, com base na pesquisa realizada.

Ao tornar facultativa a necessidade da técnica da injeção de cera no molde de silicone para replicar modelos, liberta-se o design da joia das restrições do processo de desmolde, ampliando suas possibilidades formais, equiparando-as às diversidades do mundo natural. 


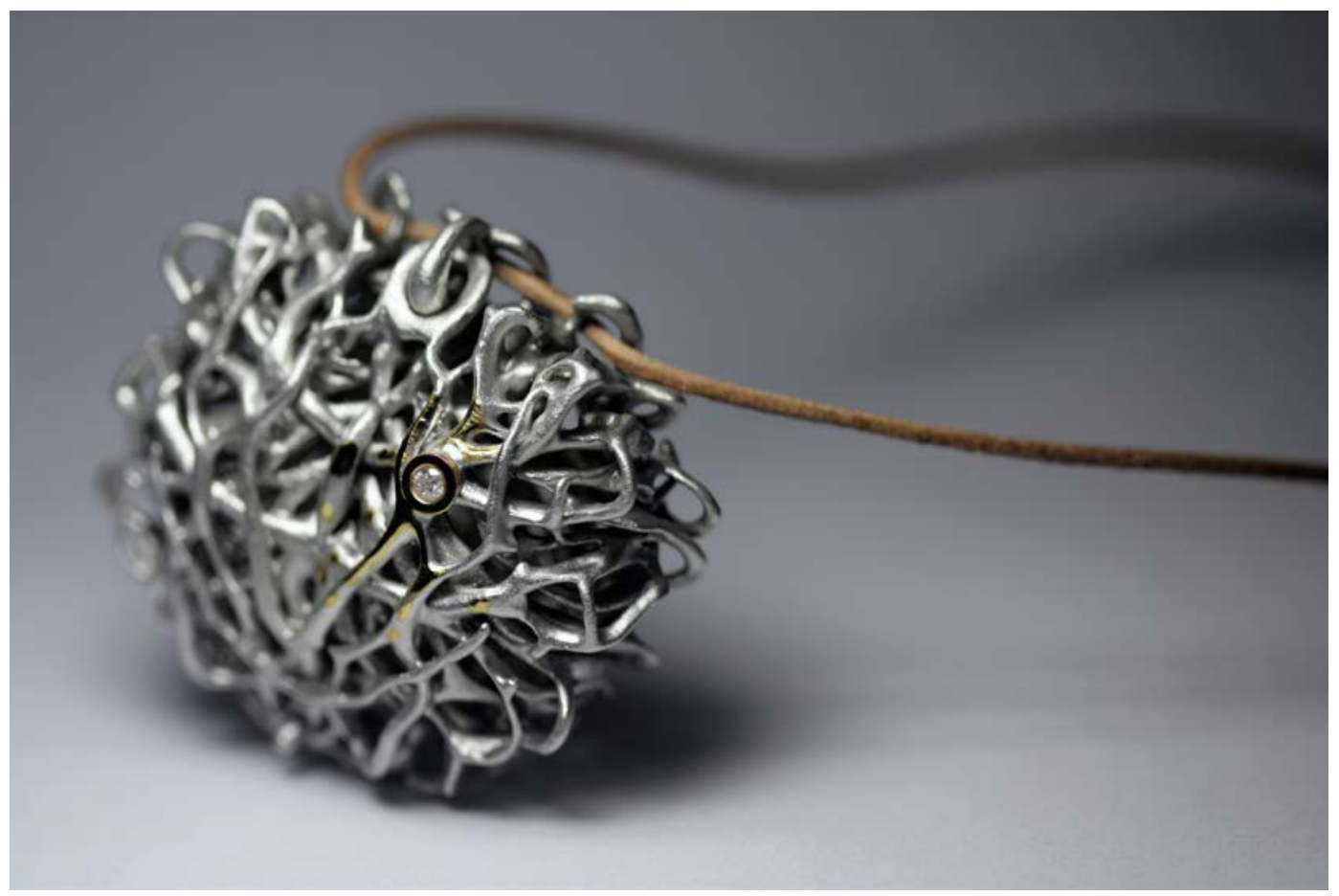

Figura 7 - Pingente Relicário finalizado.

Fonte: Elaborado pelos autores, com base na pesquisa realizada.

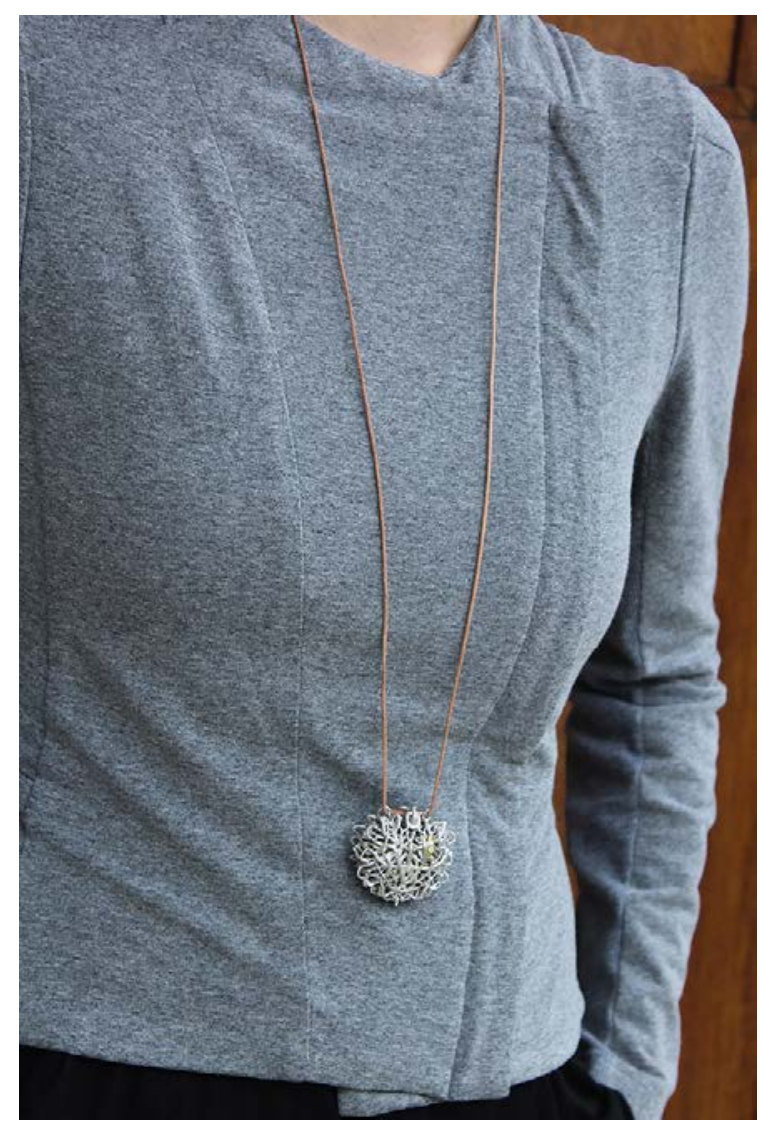

Figura 8 - Pingente Relicário em uso.

Fonte: Elaborado pelos autores, com base na pesquisa realizada. 


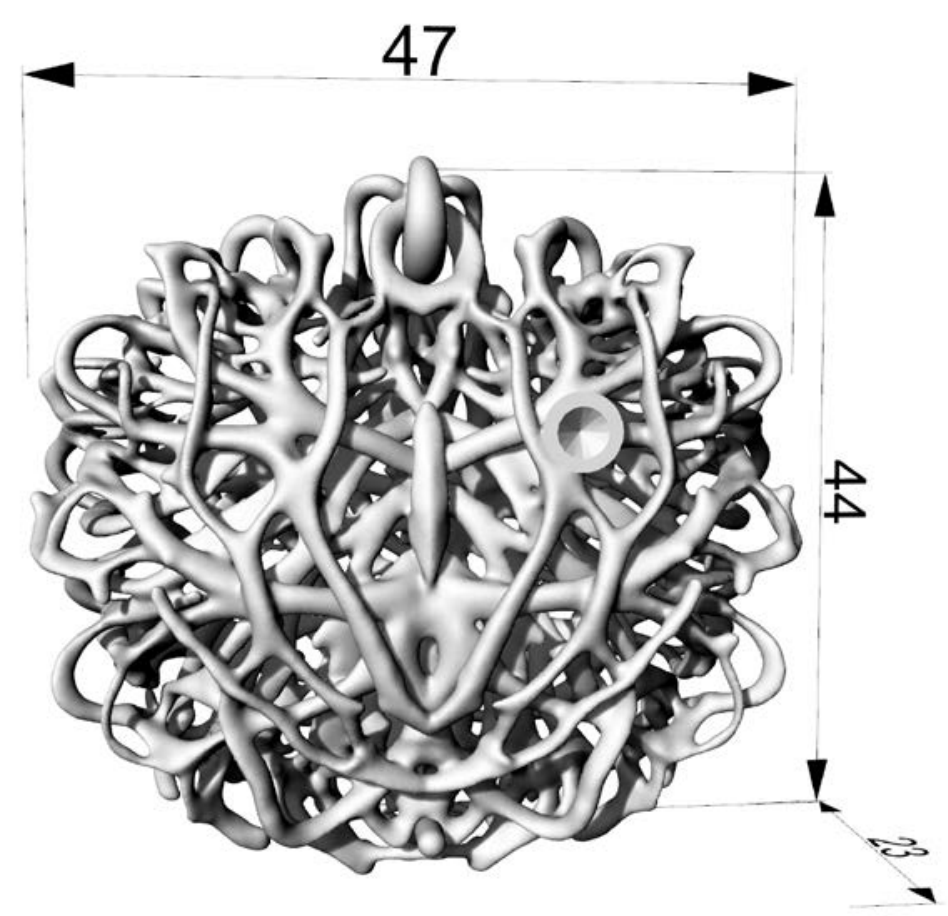

Figura 9 - Perspectiva com dimensões em milímetros do Pingente Relicário.

Fonte: Elaborado pelos autores, com base na pesquisa realizada.

\section{CONCLUSÃO}

Como já estabelecido, a Microtomografia e a Impressão 3D são processos que, quando inter-relacionados, são extremamente eficientes na produção de formas e geometrias complexas. A adição de camadas e o escaneamento por camadas são capazes, juntas, de ampliar a criatividade do designer e extrapolar no ato criativo o máximo do que cada técnica pode fornecer como ferramenta.

Além disso, com o avanço das tecnologias digitais, designers são compelidos a migrar dos meios físicos de criação para os meios digitais. Entretanto, o processo atesta que o designer também precisa complementar e correlacionar conhecimentos acerca do digital e do tradicional para promover a inovação no campo da joalheria.

Assim, o sucesso do experimento deve servir como incentivo e fomento de novos estudos que realizem a fusão do design de joias com novas tecnologias.

\section{REFERÊNCIAS}

GONZALEZ, Rafael; WOODS, Richard. Digital Image Processing. Nova lorque: AdddisonWesley Publishing Company, 1992.

DICKENS, Phill; HAGUE, Richard; HOPKINSON, Neil. Rapid manufacturing: an industrial revolution for the digital age. Chichester: John Wiley \& Sons, Ltd, 2006.

PACIORNIK, Sidnei; MAURICIO, Pinho. Digital Imaging: for materials characterization, In: ASM Handbook: Metallography and Microstructures, ASM International, Materials Park, pp. 368-402, 2004.

STOCK, Stuart R. MicroComputed Tomography: Methodology and Applications. Boca Raton: CRC Press, 2008. 